\title{
Correction to: A qualitative study of barriers to employment experienced by people living with HIV in Toronto and Ottawa
}

Melissa Perri ${ }^{1,2}$, Amy Craig-Neil ${ }^{1}$, Mark Gaspar ${ }^{2}$, Charlotte Hunter ${ }^{3,4}$, Claire Kendall ${ }^{5,6,7,8,9}$, Ower Alexander ${ }^{1}$ and Andrew D. Pinto ${ }^{1,2,4,10^{*}}$

\section{Correction to: Int J Equity Health 20, 36 (2021) DOI: 10.1186/s12939-020-01356-4}

Following publication of the original article [1], the authors identified that one of the authors' names was mentioned incorrectly. It should be as per below:

First name - Amy and last name Craig-Neil.

\begin{abstract}
Author details
${ }^{1}$ Upstream Lab, MAP/Centre for Urban Health Solutions, Unity Health Toronto, Li Ka Shing Knowledge Institute, 30 Bond St, Toronto, Ontario M5B 1W8, Canada. ${ }^{2}$ Dalla Lana School of Public Health, University of Toronto, 155 College St, Toronto, Ontario M5T 3M7, Canada. ${ }^{3}$ Casey House, 119 Isabella St, Toronto, Ontario M4Y 1P2, Canada. ${ }^{4}$ Department of Family and Community Medicine, St. Michael's Hospital, 500 University Ave, Toronto, Ontario M5G 1V7, Canada. ${ }^{5}$ Department of Family Medicine, University of Ottawa, 600 Peter Morand Crescent Suite 201, Ottawa, Ontario K1G 5Z3, Canada. ${ }^{6} \mathrm{C} . \mathrm{T}$. Lamont Primary Health Care Research Centre, Bruyère Research Institute, 85 Primrose Ave, Ottawa, Ontario K1R 6M1, Canada. Institut du Savoir Montfort, Montfort Hospital, 713 Montreal Rd, Ottawa, Ontario K1K OT2, Canada.

${ }^{8}$ Ottawa Hospital Research Institute, 501 Smyth Box 511, Ottawa, Ontario K1H 8L6, Canada. ${ }^{9} \mathrm{Li}$ Ka Shing Knowledge Institute, 209 Victoria St, Toronto, Ontario M5B 1T8, Canada. ${ }^{10}$ University of Toronto Practice-Based Research Network, 500 University Avenue, Toronto, Ontario K1H 8L6, Canada.
\end{abstract}

Published online: 07 April 2021

\section{Reference}

1. Perri $\mathrm{M}$, et al. A qualitative study of barriers to employment experienced by people living with HIV in Toronto and Ottawa. Int J Equity Health. 2021;20: 36. https://doi.org/10.1186/s12939-020-01356-4.

\footnotetext{
The original article can be found online at https://doi.org/10.1186/s12939020-01356-4

* Correspondence: andrew.pinto@utoronto.ca

${ }^{1}$ Upstream Lab, MAP/Centre for Urban Health Solutions, Unity Health

Toronto, Li Ka Shing Knowledge Institute, 30 Bond St, Toronto, Ontario M5B 1W8, Canada

${ }^{2}$ Dalla Lana School of Public Health, University of Toronto, 155 College St, Toronto, Ontario M5T 3M7, Canada

Full list of author information is available at the end of the article
}

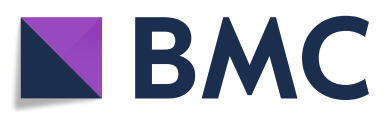

() The Author(s). 2021 Open Access This article is licensed under a Creative Commons Attribution 4.0 International License, which permits use, sharing, adaptation, distribution and reproduction in any medium or format, as long as you give appropriate credit to the original author(s) and the source, provide a link to the Creative Commons licence, and indicate if changes were made. The images or other third party material in this article are included in the article's Creative Commons licence, unless indicated otherwise in a credit line to the material. If material is not included in the article's Creative Commons licence and your intended use is not permitted by statutory regulation or exceeds the permitted use, you will need to obtain permission directly from the copyright holder. To view a copy of this licence, visit http://creativecommons.org/licenses/by/4.0/. The Creative Commons Public Domain Dedication waiver (http://creativecommons.org/publicdomain/zero/1.0/) applies to the data made available in this article, unless otherwise stated in a credit line to the data. 